Chapter 15

\title{
Benefits of Super Food and Functional Food for Companion Animals
}

\author{
Mary Ememe and Chukwuma Ememe
}

Additional information is available at the end of the chapter

http://dx.doi.org/10.5772/65946

\begin{abstract}
This chapter reviews super foods and functional foods for companion animals such as dogs, cats, and horses. Super foods are considered to be beneficial for health and wellbeing, whereas functional foods are fortified or enhanced foods that may provide a health benefit beyond the traditional nutrient they contain. Super foods for dogs and cats include blueberries, sweet potatoes, broccoli, cocoa, tomatoes, spinach, banana, strawberry, apples, carrots, coconut oil, quinoa, kale, and raw honey. Examples of functional foods for dogs and cats include omega-3-enriched egg, fatty fish, soybean oil, nuts, yogurt, and oatmeal. These food products help pets fight disease, maintain healthy skin and shiny coat, improve healthy digestion, maintain joints and strong bones, boost immune system, promote longevity, boost energy, and maintain good health in general. Many nutrients including essential fatty acids, zinc, vitamin A, vitamin E, and B-complex vitamins are now incorporated in pet foods for normal functioning of the skin and coat condition. Super foods for horses, such as pollen bee, Echinacea, and spirulina, are natural foods that have high-quality vitamins, minerals, cofactors, and enzymes. They support optimal digestive health and boost the immune system in horses. This chapter highlights the benefits derived by consuming super foods and functional foods and some specific claims supported by scientific research of these foods in companion animals.
\end{abstract}

Keywords: super food, functional food, cats, dogs, horses, nutrients

\section{Introduction}

Super food is a nonmedical, marketing term that refers to natural foods supposed to be useful for health because they are rich in a particular antioxidant or any other nutrient [1]. They are edibles that deliver the maximum amount of nutrients with minimum calories [2]. They help pets fight disease, maintain healthy skin and shiny coat, improve healthy digestion, 
maintain joints and strong bones, fight tartar and bad breath, whiten teeth, detoxify the body system, boost immune system, promote longevity, boost energy, and maintain good health in general [3]. Unlike super foods, functional foods are natural or processed foods [1]. They contain considerable levels of biologically active components that impart health benefits beyond the basic essential nutrients $[4,5]$. They also provide clinically proven and documented health benefits for the prevention, management, or treatment of chronic diseases [6]. The philosophy of food as medicine was supported by Hippocrates in approximately 400 B.C. [7]. This thinking is the foundation of functional foods used to clarify the idea that food can be a powerful deterrent and cure of many diseases and ailments. Hippocrates believed that the things eaten can help the body fend off disease and food should be the first line of disease defense, used as a disease preventative mechanism. Previous studies have provided great examples of how specific ingredients in some pets' foods can act as medicines [8]. In the past, many of the perceptions about healthy eating have focused on avoiding certain components in foods, such as fat and sugar. Nutritional research has shifted from the prevention of nutritional deficiencies, such as vitamin $C$ and scurvy or niacin and pellagra, to the prevention of chronic diseases [4]. Most pets do not receive an adequate amount of raw, essential nutrients in their diet especially in highly processed commercial pet food. Most of the natural pet foods go through a great deal of cooking, rendering, and sterilizing thereby reducing the essential nutrients [3].

Examples of super food and functional foods are oats, garlic, green tea, red grape juice, red wine, tomatoes, soy products, flaxseed, broccoli, cocoa, blueberries, carrots, sweet potatoes, pumpkin, onions, kale, cherries, and apples [9]. Oats contain beta-glucan, a soluble fiber, which aids to reduce the risk of cardiovascular disease by lowering blood cholesterol. Garlic is rich in allicin and lowers cholesterol levels and blood pressure [10]. It also stimulates immune function and slows the growth of cancer cells. Green tea contains polyphenols and may help prevent cancer [9]. Red grape juice and red wine contain resveratrol, which aids in prevention of heart disease and cancer [11]. Tomatoes contain lycopene, a carotenoid that helps to reduce risk for cancer of the colon, prostate, bladder, and pancreas $[9,12]$. Soy products (tofu, tempeh, soy milk, miso, etc.) contain genistein and isoflavones [13]. These compounds contain blood vessel formation that supplies cancer cells and hinder the body's synthesis of estrogen, thereby reducing the risk for breast, ovarian, and prostate cancer [14]. Flaxseed that contains lignans, powerful antioxidants, stops cells from becoming cancerous. It also contains alpha-linolenic acid, a type of plant omega-3 fatty acids that may lessen the risk of heart disease [9]. Broccoli has indoles that protect cells against carcinogens and aids the liver inactivate estrogen-like compounds that may sustain formation of breast cancer [2]. Cocoa has similarly been claimed to cut the risk of heart disease by lowering blood pressure and increasing the elasticity of blood vessels. This is thought to be due to cocoa's high content of compounds called flavonoids [15, 16]. Blueberries, carrots, sweet potatoes, and pumpkin provide healthy vitamins including A, $\mathrm{B}$, and $\mathrm{C}$ that are good for a healthy coat and immune system [2]. Onions, kale, cherries, and apples contain quercetin that also helps to fight cancer and heart disease [14, 17]. Other fruits that have super food status include açaí berries and pomegranates. The fruit pulp of açaí berries has been shown to have potent antioxidant properties $[18,19]$. Researchers have recognized these components and are trying to determine exactly what benefits they may present [20]. 


\section{Super foods and functional food for dogs}

Super foods and functional foods have positive effect on dogs' health and protect them against a range of diseases [2]. Figure 1 shows a dog consuming a super food.

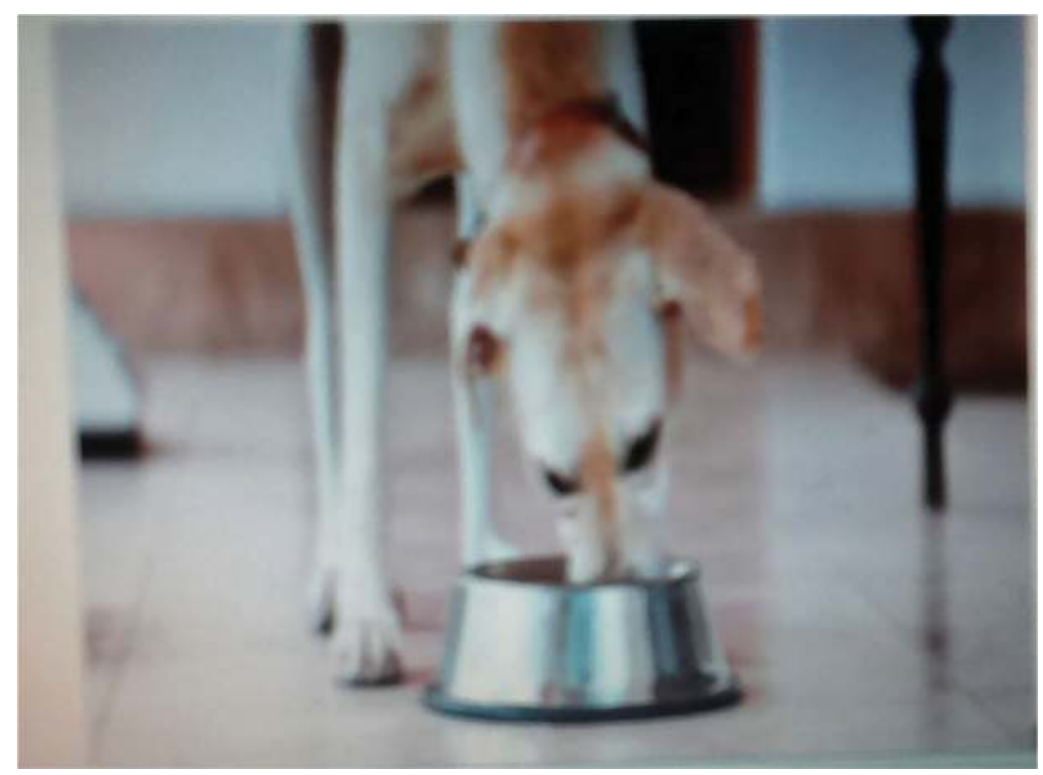

Figure 1. A dog consuming a super food [22].

Kale: It is a supercharged leafy vegetable that contains an abundant amount of vitamins, including A, E, C, K, iron, and calcium [21]. It is a good source of antioxidants and helps the liver detoxify the body. It also has anti-inflammatory properties. Kale should be avoided in pets with certain types of bladder stones or kidney disease [2].

Carrots: They are filled with carotenoids, fiber, vitamin C, K, magnesium, manganese, most of the B vitamins, phosphorus, and potassium [22]. They are packed with beta-carotene that aids in the prevention of heart disease and healthy eyesight. Carrots may be used as shavings to "bulk up" main meals in order to help fat dogs lose weight [21].

Pumpkin: It is low in calories and high in soluble fiber, pumpkin helps maintain a healthy digestive tract. It is low in sodium and exceptionally high in carotenoids, potassium, and vitamin $\mathrm{C}$, and has some calcium and B vitamins [2].

Sweet potatoes: They are super high in heart-healthy vitamin A and C and also manganese and iron that are good for a healthy coat and immune system. Their high level of fiber also aids in healthy digestion [21]. Sweet potatoes are among the top vegetables on the nutrition scale and have $150 \%$ more antioxidants than blueberries. This tuberous root vegetable acting 
as an antioxidant tackles free radicals in the body and helps in healing and disease prevention [2]. Potato fiber, a prebiotic, has been shown to promote the production of many essential molecules and shifted the microbiome in ways that may be vital to gut health [23]. A study in dogs after potato fiber was added in their diet showed that Faecalibacterium prausnitzii, a probiotic proliferated butyrate, short-chained fatty acids (SCFAs) increased and there was an overall decrease in fecal $\mathrm{pH}$ [23]. Each of these has been involved with lower incidence of infectious bowel disease.

Fish: Fish is an excellent protein source with many essential vitamins and minerals [24]. Oily fishes such as herring, salmon, sardines, mackerel, and anchovies are rich in omega-3 fatty acids [2]. Omega-3s are good for the coat and brain as well as limit inflammatory processes that cause arthritic pain and other chronic canine conditions. Moreau et al. [25] showed that after feeding diets higher in omega-3 fatty acids, there was an improvement in locomotory disability and performance in a dog showing osteoarthritis. Dogs showing atopic dermatitis (AD), a chronic and relapsing common eczematous skin disease, and fed a standardized mixture of fish, potato, and natural compounds (aloe vera, arctium lappa, malva sylvestris, and ribes nigrum) demonstrated a reduction in the overall intensity of each symptom within 20 days [26].

Oilseeds: Many prepared pet foods include omega- 6 fatty acids found in oilseeds such as sunflower, canola, and safflower. Omega- 6 fatty acids are recognized as important nutrients for reproduction, tissue repair, skin health, and coat condition [27].

Seaweed/Nori: Dried edible seaweed is a Japanese staple, often associated with sushi. It has protein, galactans (a soluble fiber), vitamins C, E and all the Bs, and minerals such as zinc and copper. B-group vitamins and zinc are a key nutrient for healthy skin and are widely incorporated into prepared pet foods to support healthy skin and coats [21].

Seaweed contains some lesser-known sterols and chlorophyll, which have been investigated for their effects on regulating metabolism [2]. Nori may have beneficial effects on fat metabolism, immune function, and antitumor response.

Sugar beet pulp: It contains fiber that is important for digestion and helps to prevent a range of serious health conditions and constipation. Dietary fiber provides bulk and helps to regulate stool volume and consistency [27]. Soluble dietary fiber gives such health benefits including careful stimulation of growth and activity of the bacteria that live in the colon. They also act as natural protective mechanism against invasion by bacteria.

Chia: The seeds of this traditional grain from Mesoamerica have numerous benefits as flax [2]. The nutritional benefits of chia include fiber, omega fatty acids, calcium, antioxidants, and protein.

Coconut oil: The "good fats" in coconut demonstrate the properties of antioxidants and boost vitamin E, promoting tissue health and shiny coats in dogs [21]. Coconut oil is over $90 \%$ saturated fat and has antimicrobial, antibacterial, and antifungal properties [28].

Raw honey: Honey is made up of simple sugars-mostly glucose and fructose that add to a range of health concerns, from obesity to diabetes [29]. Raw honey is preferred in dogs 
because it has super food health benefits [30]. This is because it has not been heat treated (pasteurized) or processed and has retained its original nutritional qualities [31]. It is typically thick and milky in appearance. Pasteurization destroys honey's beneficial properties, leaving behind a sugary, high-glycemic sweetener [29]. Feeding raw honey to dogs has such benefits including alkaline-forming, high in antioxidants, containing natural enzymes and nutrients, powerful antibacterial and antimicrobial properties, helps heal ulcers, helps manage diarrhea, and aids indigestion [32]. Raw honey is also helpful in treating topical wounds, including sunburns and mild burns. This is due to the chemical reaction that occurs between glucose in the honey and an enzyme added by honeybees called glucose oxidase. When the honey comes in contact with the skin, glucose oxidase breaks down the glucose into hydrogen peroxide, which is antibacterial. Pasteurized honey, however, is not beneficial for wound treatment [29]. Also consumption of locally grown raw honey helps to prevent seasonal pollen allergies because locally grown raw honey has local pollen spores taken up by the bees, hence consumption leads to gradual production of immunity to the pollen [33, 34]. Manuka honey is the most useful of all honeys. In clinical trials, Manuka honey has helped to destroy bacteria such as methicillin-resistant Staphylococcus aureus, methicillin-sensitive S.aureus, vancomycin-resistant enterococci, and Helicobacter pylori [31]. Raw honey should be fed in moderate amount to dogs, a teaspoon per day for small dogs and a tablespoon per day for large dogs. Care should be taken especially in diabetic or overweight dogs. Puppies should not eat raw honey, as it can potentially be contaminated with a botulism-related toxin which their immature immune systems are unable to defend [29].

Blueberries: They are filled with antioxidants known to boost cognitive function in dogs [21]. Blueberries are one of the most popular and well-known super foods, and have been studied frequently by scientists curious about their health properties [35]. The high concentrations of antioxidant and anthocyanins inhibit the growth or kill cancerous human colon cells [36]. Blueberries are also rich in other antioxidants that may prevent and reverse age-related memory decline in rats [37].

Quinoa: It is packed with protein; studies have reported that quinoa is also associated with preventing heart disease and cancer. Because it is nutritionally denser than most processed carbohydrates, it makes an excellent rice and grain alternative [21].

Natural peanut butter: A tasty source of protein used to build and repair muscle tissue; peanut butter is filled with "good fats" that support a healthy cardiovascular system. Caution should be taken while feeding pups with peanut butter as it is high in calorie [21].

\subsection{Super foods and functional food for cats}

Dandelion: Dandelion leaves and roots may relieve feline allergies and aid with healthy digestion. Roots of pesticide-free dandelions are mostly useful in liver detoxification. Cats sometimes chew the plants hence these help to get a little roughage in their diet [38].

Cranberries: The nutrients in this super berry are known for preventing recurrent urinary tract infections and promoting overall urinary and kidney health [38]. Cranberry is packed with antioxidants and anticancer agents. 
Yogurt: Plain (not vanilla or sweetened) whole-milk yogurt is good for cats. Yogurt is rich in protein and calcium, and it is a great source of probiotics [39]. Lactose is already broken down with the culturing of the yogurt, and milk proteins are either removed or reduced, hence it is simple and delicious for cats to digest. It is recommended that cat is gradually introduced to yogurt consumption to avoid allergic reactions [38].

Lean meats: This is a top cat super food. Lean meats such as cooked chicken, beef, or pork with no noticeable fat boost protein in cat's diet. Lean meat is an excellent source of iron and B vitamins, which are involved in kitty's energy metabolism [38]. Fat trimmings should be avoided as too much fat at one sitting puts cat at risk of pancreatitis.

Fish: Fish is a great source of lean protein and omega-3 fatty acids [24]. Oily fishes, such as salmon, sardines, and anchovies, have benefits of omega-3s without doses of mercury [40]. The omega-3 fatty acids in salmon and other oily fish may prevent heart problems in people with a high-cardiovascular risk, as well as ease joint pain experienced by patients with rheumatoid arthritis [24]. These healthy fats have been shown to help cats' coats stay shiny and lustrous to fighting cancer. Most pet foods are heavy on omega-6s, which are proinflammatory. Therefore, to balance the ratio in the body and reduce the danger of inflammation, cats should be fed a diet rich in the omega-3s docosahexaenoic acid (DHA) and eicosapentaenoic acid (EPA) [39].

Eggs: Eggs are a super source of protein and very easy to digest. They also contain essential amino acids responsible for keeping kitty lean and muscular. Cooked eggs are preferable as there are problems with serving cat raw eggs [39]. There is the possibility of food poisoning and protein in raw egg whites, called avidin, interferes with the absorption of the vitamin B biotin, which cat needs for healthy skin and shiny coat [40].

A good rule of thumb is that these super foods and functional foods for cats should not make up more than $15 \%$ of their diet [38]. Figure 2 indicates a cat being fed on super food.

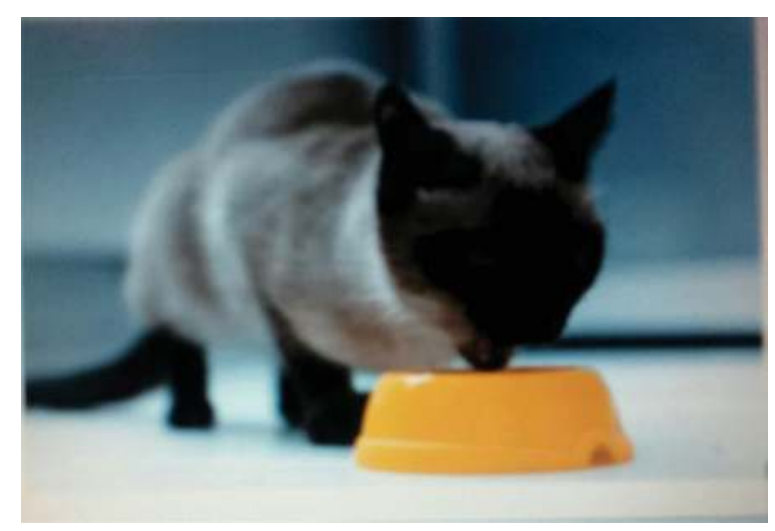

Figure 2. A cat consuming a super food [38]. 


\subsection{Super foods and functional foods for dogs and cats}

Goat's milk: It is a new super food for dogs and cats. It contains very small or no casein at all unlike cow milk. Casein, along with other different proteins, makes cow's milk much more difficult to digest, increasing the likelihood of allergic reactions [41]. Goat milk does not cause much allergic reaction. Previous studies have shown that the fat present in goat milk is very easily absorbed, and the higher concentration of short- and medium-chain fatty acids significantly enhances digestibility. Goat milk also has high amounts of enzymes, vitamins, minerals, trace elements, vital electrolytes, and the naturally occurring prebiotics (fructooligosaccharide) as a possible aid in the treatment of diabetes [41].

Avocado: It may be one of the best sources of essential nutrients for dogs or cats as one powerful super food [42]. Persin is a substance found in the avocado pit, skin, bark, leaves and is harmful to some animals such as birds, rabbits, horses, and goats. However, there have been no reported cases of avocado poisoning in dogs and cats [42].

\subsection{Super foods and functional food for horses}

Feeding super foods promote a naturally healthy horse. Feeding high-quality super foods is healthier than feeding highly processed foods. Most horse feeds include probiotics and prebiotics, which aid in enhancing the general digestibility of horse's diet, reduce susceptibility to pathogenic bacteria, and improve immune system [43]. Super foods for horses, such as pollen bee, Echinacea, and spirulina, have high nutritional value in the most bioavailable form for horses [44]. This means the horse's body will fully utilize this type of nutrition and receive multiple benefits due to easy absorption of the nutrients and their synergistic properties [45].

Spirulina: Spirulina (Figure 3) is a type of blue-green algae (BGA), which is rich in protein, vitamins, minerals, and carotenoids [46]. There are numerous reports in the veterinary literature of BGA down-regulating inflammation in colitis, liver disease, joint disease, and neuropathic pain in horses [47]. It is useful for a variety of equine conditions; it is used in horses for lung allergy issues. Spirulina is probably best known for its ability to boost the immune system. It is high in protein (55-70\%), amino acids, vitamin B-12, and vitamin E. It contains essential fatty acids including gamma-linoleic acid (GLA) for heart and joint health. It contains high concentrations of all minerals including trace minerals [45]. It specifically improves the production of IgG antibodies, while down-regulating allergies associated with IgA antibody responses [48]. Spirulina supplementation can improve such equine conditions including Heaves/chronic obstructive pulmonary disease (COPD)/asthma, seasonal respiratory allergies, hives and other skin allergies, sweet itch (summer eczema), and poor immune function. It is easily digestible and highly bioavailable [46].

Psyllium: Studies have shown that feeding a daily dose of psyllium can effectively limit the severity of hindgut ulcers and may aid in the prevention of their occurrence [49]. It creates a barrier and limits the intestinal absorption of acids thus decreasing the incidence of ulcer- 
ation. Multiple studies have evaluated the benefits of psyllium's daily use in horses who struggle with right dorsal colitis. Intestinal bacteria ferment psyllium to produce short-chain fatty acids that can aid in the healing of mucosal tissues [50]. Feeding psyllium to horses can actually lower blood glucose and insulin levels [51]. This may aid to ameliorate conditions such as equine metabolic syndrome, insulin resistance, Cushings, and many other common metabolic issues. When psyllium is fed in its proper form, psyllium has the ability to support optimal digestive function. By coating the intestinal lining, it allows for the effective movement of feed and debris through the digestive tract while also promoting maximum absorption of nutrients and water [52].

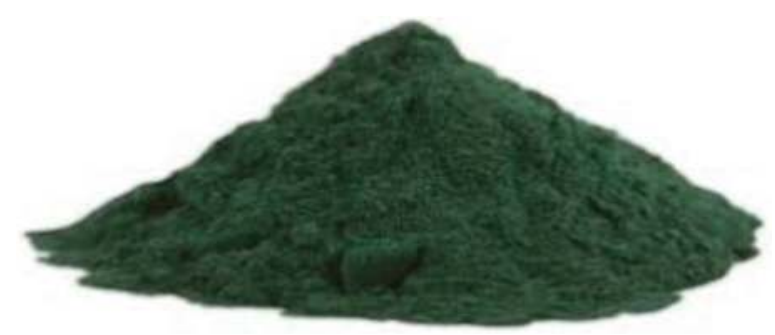

Figure 3. Spirulina powder [48].

Bee pollen: It contains high concentrations of living enzymes. It is good for older horses or those that have inadequate grazing. Bee pollen contains a full range of super whole food vitamins, minerals, coenzymes, antioxidants, and amino acids. It has helped older horses maintain their muscle tone as they age [45]. Pollen contains high concentrations of living enzymes. However, high heat destroys enzymes; therefore, it is essential that the form is raw whole food. Bee is collected from flower pollen and is a natural food for horses, and can bring them into a healthy springtime bloom anytime of the year [53]. There are numerous reports of the benefits of supplemented bee pollen in horses including improved oxygen utilization, lower heart rates, and firmer muscle tone [54]. A recent pilot study in horses demonstrated bee pollen supplementation on physical fitness parameters, immunological status, and nutritional variables in Arabian horses in training. It was observed that supplementation with a commercial $55 \%$ bee pollen for 42 days did not change physical fitness or immunological variables in the horses but it significantly increased feed consumption and nutrient retention in the same horses [54].

Echinacea: A popular herb (purple coneflower, a common ornamental garden plant) stimulates the immune system and helps fend off opportunistic infections such as the common cold. The equine industry typically uses Echinacea as an immune booster to compliment a healthy immune system [55]. Studies by Briggs [56] showed that Echinacea is an immunostimulant and a hematinic agent in horses. Echinacea is known for its antiviral, antibacterial, antioxidant, and anti-inflammatory properties [57]. This is an exceptional herb given to 
horses usually during seasonal changes when there is likelihood for illness [45]. A study was carried out on eight horses using an Echinacea preparation called Echi-Fend, manufactured by Quinte Botanicals, a division of Bioniche Life Sciences. They were fed $30 \mathrm{ml}$ of Echi-Fend twice a day for 6 weeks and an inactive placebo for another 6 weeks. Blood samples were taken every week and complete hematology and biochemistry screens along with phagocytic function test were carried out. The study showed some effects: while on Echi-Fend, the horses showed a significant increase in the size and the number of circulating red blood cells, as well as an increase in the level of hemoglobin and lymphocytes in the blood. In addition, there was a significant decrease in the levels of circulating neutrophils in the blood. This study clearly demonstrated that Echinacea acts both as an immuno-stimulant and a hematinic agent in horses [56].

Colostrum: It is a complex fluid, rich in nutrients and immune-regulating compounds [58]. Immunoglobulins found in colostrum are very large proteins, far too large to be absorbed directly into the bloodstream at an advanced age. In adult animals, most of these proteins are degraded by digestive enzymes, but some portion of these large molecules is transported across the intestinal lining intact, where it binds to an antigen [59]. Hence, supplementing colostrum to adults horses impacts on their health. Colostrum also protects overall well-being by providing a wide range of factors including lactoferrin, oligosaccharides, peptides, leukocytes, and growth factors [60]. Colostrum from cows is richer in immunoglobulins than from other animal species, thereby offering improved protection against viral and bacterial infections. It is also very low in lactose, making it appropriate for adult horses (who are naturally lactose intolerant) [61]. Other researchers have identified improvements in disorders such as obesity, insulin resistance, leaky gut syndrome, and ulcers $[62,63]$. Colostrum supplementation has helped to improve performance in horses by its apparent ability to stimulate neutrophil's oxidative response following prolonged exercise [64].

Fructo-oligosaccharides (FOS): A type of prebiotic, specialized sugars that are super food for bugs to encourage the development of healthy intestinal flora [65]. They give resident microflora (good bacteria) a competitive advantage over pathogenic bacteria and strengthen the stability of the essential flora. The colon and the good bacteria have an essential role in the extraction and assimilation of nutrients to face the daily and sporting requirements but most notably to guarantee the health of the equine athlete [66].

\section{Conclusion}

Feeding super foods and functional foods to companion animals provides multiple health benefits. Such foods help maintain good immune response, body hair coat, digestive health, locomotion, and general well-being. More investigations need to be carried out to identify other super foods and functional foods for companion animals and determine precisely what benefits they may boast. 


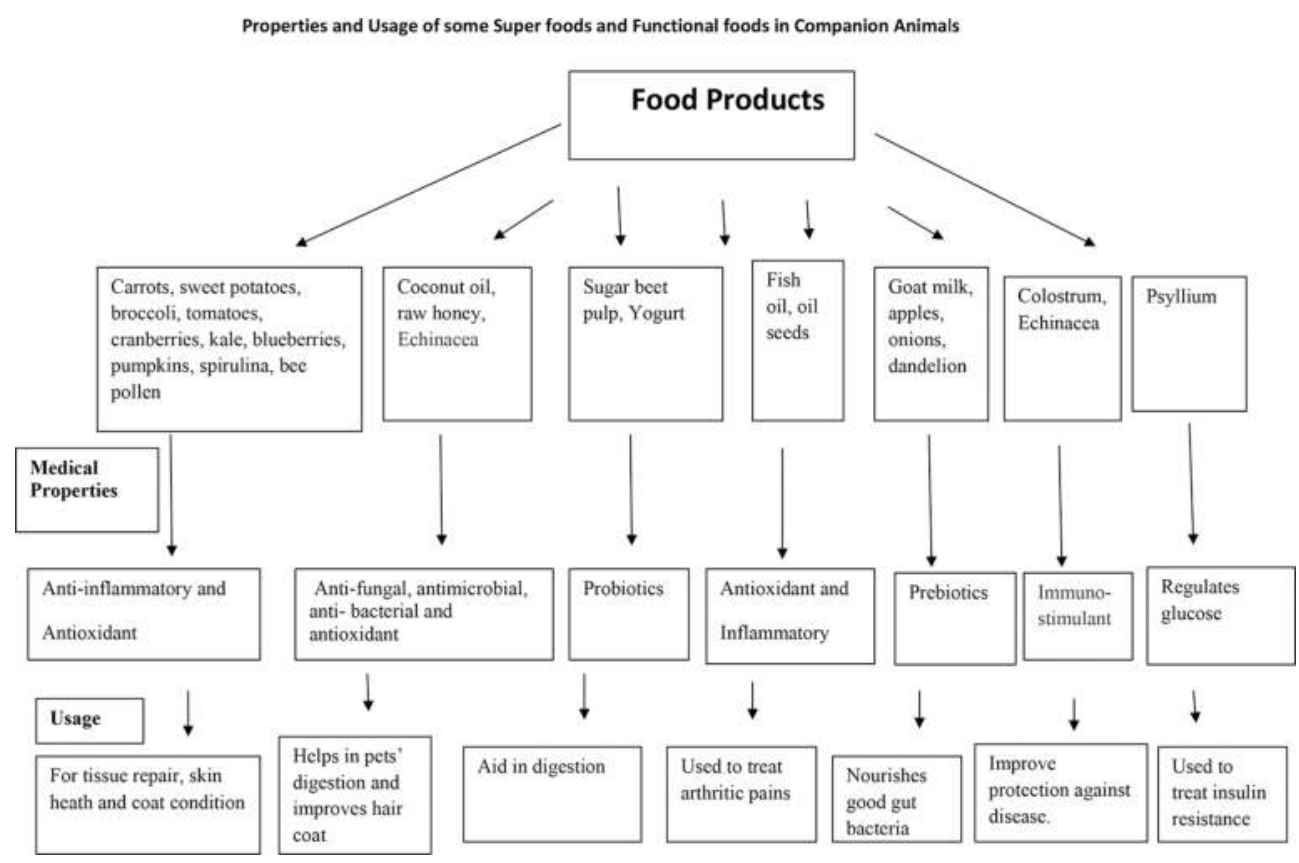

\section{Author details}

Mary Ememe* and Chukwuma Ememe

*Address all correspondence to: maryeneme@yahoo.com

Department of Veterinary Medicine, Michael Okpara University of Agriculture, Umudike, Nigeria

\section{References}

[1] Lifestyle Health. Functional vs Super Foods. 2016. Available from: www.modelandmore.com/health/antioxidant/superfoods/functionalfoods. Accessed: 2016-5-16.

[2] Kawezynska C. Ten Super Foods for You and Your Dog. 2016. Available from: The Bark Inc. Accessed: 2016-5-16.

[3] Mother Earth Pet Products. SuperEssentials for Dogs and Cats. 2016. Available from: https://motherearthpet.com . Accessed: 2016-7-31. 
[4] Klotzbach K. Phytochemicals and Functional Foods: Super Foods for Optimal Health. 1999. Rutger Cooperative Research and Extension NJAES. The State University of New Jersey. Desktop Publishing by Rutgers Cook College Resource Centre.

[5] USDA-ARS. Basics about Functional Food. 2015. Available from: http://www.ars.usda. gov/SP2UserFiles/Place/00000000/NPS/FinalFunctionalFoodsPDFReadVersion6-25-10. pdf. Accessed: 2016-5-16.

[6] Martirosyan D, Singh J. A new definition of functional by FFC: what makes a new definition unique? Review article. FFHDJ. 2015. 5(6):209-223.

[7] Jones WHS. Functional Foods. Hippocrates. 1932. New York, Heinmann. p. 351.

[8] Slimdoggy. What are functional foods? 2016. Available from: https://www.pinterest. com/slimdoggy. Accessed: 2016-8-25.

[9] Clevidence B. Phytochemicals. Am Diet Assoc. 1997. 97 (Suppl 2):s199-s204

[10] LaChance PA. Nutraceuticals: Designer Foods: Garlic, Soy, Licorice Food and Nutrition. 1997. Trumball, CT, Press.

[11] Zordoky BNM, Robertson IM, Dyck JRB. Preclinical and clinical evidence for the role of resveratrol in the treatment of cardiovascular diseases. Bio chim Biophys Acta. 2015.1852(6):1155-1177. Doi10.1016/j.bbadis2014.10.016

[12] Holistic Pet. The Benefits of Antioxidant Supplements for Dogs and Cats. 2016. Available from: holistic pet info.com. Accessed: 2016-5-16.

[13] IFIC (International food information council) Functional Foods Now. 1999. Washington, DC: International Food and Information Council.

[14] Herman C, Adlecreutz T, Goldin BR, Gorback SL, Hockerstedt KA, Watanabe S, Hamalainen EK, Markkanene MH, Makela TH, Wahala KT, Hase TA, Fostis T. Soybean and phytoestrogen intake and cancer risk. Nutrition. 1995. 125:757S-770S.

[15] Kris-Etherton PM, Keen CL. Evidence that the antioxidant flavonoids in tea and cocoa are beneficial for cardiovascular health. Curr Opin Lipidol. 2002. 13:41-49.

[16] Hooper L, Rimm EB, Cohn JS, Harvey I, Le Cornu KA, Ryder JJ, Hall, WL, Cassidy A. Flavonoids, flavonoid-rich foods, and cardiovascular risk: a meta-analysis of randomized controlled trials. Am J Clin Nutr. 2008. 88(1):38-50.

[17] Buring JE, Hennekens GH. Beta-carotene and cancer prevention. J Cell Biochem. 1995. 22(Suppl):226-230.

[18] Lichtenthär R, Rodrigues RB, Maia JG, Papagiannopouos M, Fabricius H, Marx F. Total oxidant scavenging capacities of Euterpe oleracea Mart (Açaí) fruits. Int J Food Sci Nutr. 2005. 56(1):53-64. 
[19] Hassimotto NMA, Genovese MI, Lajolo FM. Antioxidant activity of dietary fruits, vegetables, and commercial frozen fruit pulps. J Agric Food Chem. 2005. 53:2928-2935.

[20] Block G, Paterson B, Subar A. Fruit, vegetables, and cancer prevention: a review of the epidemiological evidence. Nutr Cancer. 1992. 18 (1):1-29.

[21] Fuzzyard Seven Super foods for Dogs. 2013. www.Fuzzyard.com. Accessed: 2016-5-17.

[22] VanEastVet. What to Feed Your Pet: Seven Superfoods (For Dogs) and Ten Foods to Avoid. 2015. Available from: https://vancouvereast.vet. Accessed: 2016-8-1.

[23] Panasevich MR, Keer KR, Dilger RN, Farhey Jr GC, Guerin-Deremaux LG, Lynch GI, Wils D, Suchodolski JS, Steiner JM, Dowd SE, Swanson KS. Modulation of the fecal microbiome of healthy adult dogs by inclusion of potato fiber in the diet. Br J Nutr. 2015. 113:125-133. Doi: 10. 1017/50007.114514003274

[24] Kris-Etherton PM, Harris WS, Appel LJ. Fish consumption, fish oil, omega-3 fatty acids, and cardiovascular disease. Arterioscler Thromb Vasc Biol. 2003. 23:e20-e30.

[25] Moreau M, Toroncy E, DelCastillo JR, Bedard C, Gauvin D, Lussier B. Effects of feeding a high omega-3 fatty acids diet in dogs with naturally occuring osteoarthritis. J Anim Physiol Anim Nutr (Berl). 2015. 397(5):830-837. Doi: 10.1111/j1439-6396,2012.01325

[26] Di Cerbo A, Palmieri B, Chiavolelli F, Guidetti G, Canello S. Functional foods in pets and humans. Int J Appl Res Vet Med. 2014.12:3.

[27] PFIAA (Pet Food Industry Association of Australia Inc). Functional Foods and Advances in Pet Nutrition. 2016. Available from: www.pfiaa.com.au. Accessed: 2016-5-17.

[28] Groskopp T. Coconut Oils: Natural Healthy Concept. 2016. Available from: www.natural healthyconcept.com. Accessed: 2016-8-1.

[29] Laverdure DR and Dodds WJ. Raw Honey - A Canine Superfood. Adapted from Canine Nutrigenomics: The New Science of Feeding Your Dog for Optimum Health. 2015. Available from: http://petfooddiva.com. Accessed: 2016-5-17.

[30] Mercola J. The Healing Properties of Raw Honey. Available from: http://arti-cles.mercola.com/sites/articles/archive/2006/12/19/the-healing-properties-of-honey.Aspx 2006. Accessed: 2016-5-17.

[31] Mercola J. This Bee Product has Enormous Benefits for Your Health. 2009. Retrieved from: http://articles.mercola.com/sites/articles/archive/2009/11/17/This-Bee-Prod-uct HasEnormous-Benefits-for-Your-Health.aspx. Accessed: 2016-5-17.

[32] Mercola J. Fresh evidence Could 1 Teaspoon Per Day Tame Your Allergy Problems? 2011. Available from: http://articles.mercola.com/sites/articles/archive/2011/05/27/caneating-local-honey-cure-allergies.aspx. Accessed: 2016-5-17.

[33] Puotinen CJ. Bee Products have a Special Meaning for Dogs. 2007. Available from: http://www.whole-dog-journal.com/issues/10_9/features/Bee-Honey-Products-HelpCanines_15967-1.html. Accessed: 2016-5-17. 
[34] Saarinen K, Jantunen J, Haahtela T. Birch pollen honey for birch pollen allergy - a randomized controlled pilot study. Int Arch Allergy Immunol. 2011. 155:160-166. Doi: $10.1159 / 000319821$

[35] EUFIC (European Food Information Council). The science behind super foods: are they really super? 2012. Available from: http://www.eufic.org. Accessed: 2016-5-17.

[36] Yi W, Fischer J, Krewer G, Akoh CC. Phenolic compounds from blueberries can inhibit colon cancer cell proliferation and induce apoptosis. Agric Food Chem. 2005. 53(18):7320-7329.

[37] Malin DH, Lee DR, Goyarzu P, Joseph JA. Short-term blueberry-enriched diet prevents and reverses object recognition memory loss in aging rats. Nutrition. 2011. 27(3):338-342.

[38] Schaible L. 6 Superfoods For Cats (Yes, They Do Exist!) Human and Dog Super Foods Get their Share in the Nutrition Spotlight, but What about our Forgotten Felines? 2015. Available from: http://www.petcha.com/petcare. Accessed: 2016-8-1.

[39] Ward E. The Fab Five: Five Superfoods to Feed Your Pet. 2013. Available from: http:// www.gopetplan.com. Accessed: 2016-7-31.

[40] White S. 5 Amazing Super Foods for Dogs \& Cats. 2016. Available from: http://www. styletails.com. Accessed: 2016-7-31.

[41] Gottlieb M. Goat's Milk The New Super Food for Dogs \& Cats. 2015. Available from: http://www.goodpet.com. Accessed: 2016-8-1.

[42] Dodds J. The Truth About Avocados and Your Dog or Cat Central Garden \& Pet Company. 2014. Available from: http://www.avacadofactsfordogsandcats.com/dogs. html. Accessed: 2016-8-1.

[43] Vandergrift B. Functional Ingredient in Horses. 2016. Available from: www.retiredracehorse project.org/index.php. Accessed: 2016-9-22.

[44] Taylor J. Equine Super Foods with Dr. Carol Michael. 2015. Accessed: 2016-5-17.

[45] Krahl S. Do You Feed These 3 Beneficial Super Foods to Your Horses? Soulful Equine. 2016. Available from: www.soulfulequine.com. Accessed: 2016-5-17.

[46] Casie B. Spirulina (Blue Green Algae). The Naturally Healthy Horses. 2013. Horse Journal: Guide to Equine Supplement and Nutraceutical. Accessed: 2016-5-17.

[47] Pearson W. Spirulina for Horses: A Mighty Immune Modifier. 2015. Can. Horse J. www. horseherb.com. Accessed: 2016-8-1.

[48] Kellon EM. Guide to Equine Supplements and Nautraceuticals. 2008. Horse J. http:// www.pinterest.com. Accessed 2016-08-26. 
[49] Sahagun AM, Vaquera J, Garcia JJ, Calle AP, Diez M, Fernandez N, Loro JF, Portilla HO, Sierra M. Study of the protective effect on intestinal mucosa of the hydrosoluble fiber Plantago ovata husk. BMC Complement Altern Med. 2015. 15:298.

[50] Reuss SM. Updates in the medical management of colic: moving beyond mineral oil. AAEP Proc. 2014. 60:213-218.

[51] Moreaux S, Nichols J, Bowman J, Hatfield P. Psyllium lowers blood glucose and insulin concentrations in horses. J Equine Vet Sci. 2011. 31(4):160-165.

[52] Mills A. Psyllium: Sand Clearance or Equine Super Food. 2016. http//arenus.com. Accessed: 2016-5-17.

[53] Springtime. Bee Pollen for Horses. 2015. https//www.springtimeinc.com. Accessed: 2016-8-1.

[54] Turner KK, Nielsen BD, O'Connor CI, Burton JL. Bee pollen product supplementation to horses in training seems to improve feed intake: a pilot study. J Anim Physiol Anim Nutr. 2006. 90:414-420.

[55] Anon. Herbs \& Remedies for Fabulously Healthy Animals. 2003. Brookby Herbs, Clevedon, NZ. www.brookbyherbs.co.nz Accessed: 2016-8-1.

[56] Briggs K. Ecchinacea Proven Effective in Horses. The horse.com. 2001. Accessed: 2016-8-1.

[57] Williams CA, Lamprecht ED. Some commonly fed herbs and other functional foods in equine nutrition: a review. Vet J. 2008. 178(1):21-31. Doi:10.1016/j.tvjl.2007.06.004

[58] Getty JM. Is Colostrum the Horse World's Latest Superfood? Horsetalk. co.nz. 2016. Accessed: 2016-8-1.

[59] Hurley WL, Theil PK. Perspectives on immunoglobulins in colostrum and milk. Nutrients. 2011. 3:442-474.

[60] Playford RJ, Macdonald CE, Johnson WS. Colostrum and milk-derived peptide growth factors for the treatment of gastrointestinal disorders. Am Clin Nutr. 2000. 72:5-14.

[61] Li-Chan E, Kummer A, Losso JN, Nakai S. Survey of immunoglobulin G content and antibody specificity in cow's milk from British Columbia. Food Agric Immunol. 1994. 6:443-451.

[62] Kim JH, Jung WS, Choi NJ, Kim DO, Shin DH, Kim YJ. Health-promoting effects of bovine colostrum on Type 2 diabetic patients can reduce blood glucose, cholesterol, triglyceride and ketones. J Nutr Biochem. 2009. 20:298-303.

[63] Kompare J. Leaky gut syndrome in horses. Master's Thesis, Michigan State University, Department of Animal Science. 2013. 
[64] Jones AW, Thatcher R, March GS, Davison G. Influence of four weeks of bovine colostrum supplementation on neutrophil and mucosal immune responses to prolonged cycling. Scand. J Med Sci Sports. 2015. 25:788-796.

[65] Sabater MM, Larque E, Torrella F, Zamora S. Dietary fructooligosaccharides and potential benefits on health. J Physiol Biochem. 2009. 65(3):315-328. Doi:10.1007/BF03180584

[66] Janicki KM. Pre- and Probiotics for Horses. 2012. Blood-Horse Publications. The horse.com 2012 Accessed: 2016-8-1. 
